\title{
INVESTIGACIÓN, DOCENCIA Y TECNOLOGÍA
}

\author{
Omar Parra Rozo* \\ Recibido: mayo 30 de 2006 - Revisado: agosto 18 de 2006 - Aceptado: septiembre 5 de 2006 \\ La ciencia experimental que Francis Bacon profetizó nos ha dado ahora la cibernética, que ha permitido que \\ Ios hombres pisen la luna y cuyas computadoras son, si la frase es lícita, tardías hermanas de los ambiciosos \\ redondeles de Lulio.
}

Mauthner observa que un diccionario de la rima es también una máquina de pensar.

Jorge Luis Borges

\section{Resumen}

El presente artículo hace parte del proyecto investigativo institucional PROIN, del que se han realizado los siguientes productos: Gestión, investigación y narrativa; La gestión es cosa de niños; La investigación es un cuento de Hadas; ¿Qué perseguimos al buscar la verdad?; La investigación es un placer; y Gestión, investigación y narrativa: investigar es un juego.

La reflexión sobre las nuevas tecnologías y su influencia en las tendencias educativas de la actualidad proporcionan elementos para profundizar en la pedagogía, la investigación y el conocimiento. Sin embargo, la propuesta tecnológica varía constantemente y el auge de la información origina un intercambio permanente de mensajes. En este artículo se plantea la necesidad de encontrar lo esencial del aprendizaje y de la investigación a través de diversos acercamientos y fuentes. Desde esta perspectiva, se analiza la importancia de los bloques de información que brindan diversos contenidos conceptuales en la producción y acceso al conocimiento y estructuran una nueva práctica pedagógica e investigativa. Las nuevas tecnologías de información pueden representar una amenaza a la forma tradicional de investigar, enseñar y aprender 0 , por el contrario, pueden constituirse en una herramienta valiosa que complementa y brinda elementos que actualizan y consolidan los diversos procesos.

Doctor en Literatura, Magíster en Administración Educativa y Especialista en Educación a Distancia. Líder de dos grupos de investigación reconocidos por COLCIENCIAS: "Relaciones, redes y narrativas" (Categoría A), "Gestión, investigación y narrativa" (Categoría B). Correo electrónico: omarparra@correo.usta.edu.co. 


\title{
Palabras clave
}

Información, investigación, conocimiento, TIC, aprendizaje, blogs, lenguaje, ciencia.

\begin{abstract}
This article is a part of the PROIN Investigative Institutional Project, from which it has been taken into account the following products: Negotiation, investigation and narrative; Negotiation is a matter of children, investigation is a fairy tale; what do we expect to search the truth? Investigation is a pleasure and negotiation, investigation and narrative: To investigate is a game.

Reflection on new technologies and their influence in educative trends nowadays provide elements to deepen in pedagogy, investigation and knowledge. However technological proposal changes constantly and the apogee of information create a permanent interchange of messages in this article it tried the need of finding the essential of learning and investigation though different approaches and sources. From this perspective it is analyzed the importance of blocks of information that provide different conceptual contents in the production and access to knowledge that structure a new practical and investigative pedagogy. New information technologies can represent a threat related to the traditional ways of investigating, teaching and learning, or on the contrary, they can constitute a valuable tool that complements and offers elements that modernize and consolidate the different processes.
\end{abstract}

\section{Key words}

Information, investigation, knowledge, learning, blogs, language, science.

\section{Introducción}

Este producto investigativo se inserta dentro del proyecto interdisciplinario investigativo que adelantan dos grupos de investigación ${ }^{1}$, los cuales indagan, desde sus líneas particulares, por la gestión, la narrativa y la integración de la investigación como elementos primordiales dentro de la construcción del conocimiento. En uno de los productos anteriores La gestión de la investigación es cosa de niños, se plantean las posibilidades de la indagación a partir de la búsqueda y la construcción de la verdad, haciendo un paralelo entre el proceso investigativo científico y la creatividad infantil. En el siguiente trabajo, La investigación es un cuento de hadas, la búsqueda se profundizó con la revisión de autores de literatura infantil, lo mismo que representantes de otras disciplinas como la física y las matemáticas. Tópicos como el método, los obstáculos epistemológicos, el trabajo de gestión, la creatividad, la pregunta y el problema, entre otros, son elaborados desde un lenguaje que pretende hacer de la investigación un camino placentero, que, sin desviarse de la seriedad y la cientificidad, es asequible a quien guste de la misma y a quien disfrute sumergiéndose en el ámbito cuantitati-

\footnotetext{
Tanto el grupo de investigación Relaciones, redes y narrativas, Categoría A-Colciencias, como el grupo Gestión, investigación y narrativa, Categoría B-Colciencias, tienen sendos proyectos investigativos que indagan por los aportes que brindan al proceso de investigación las diversas disciplinas y tópicos del conocimiento, apuntando a una combinación entre lo científico, lo artístico y lo "humano". La desmitificación de un proceso no implica que se demerite el mismo, o se desgaste. Por el contrario, se busca el enriquecimiento desde otros puntos de vista y la búsqueda de la esencia investigativa propiamente dicha, tanto en el diario transcurrir como en el más complejo proceso investigativo y tanto en los intrincados vericuetos científicos como en los ingenuos y creativos juegos infantiles. Las relaciones dadas implican elementos determinantes en la conjugación didáctica, docente, tecnológica e investigativa.
} 
vo tanto como en el cualitativo. En la tercera fase del proyecto, presentamos como producto terminal otro planteamiento referente a la búsqueda de la verdad y el trabajo en equipo, dando paso a la relación que se establece entre el juego, la investigación y el placer, considerando sus actores, los respectivos procesos y los elementos intervinientes que hacen de este proceso creativo y complejo una posibilidad de sobrevivencia y de permanencia en un mundo globalizado y totalizante. La investigación, la docencia y la gestión constituyen un referente obligado para explicar la realidad, el contexto y para transformarnos o adaptarnos a ellos, para encontrar puertas que brinden nuevos horizontes 0 , paradójicamente, para abrir el cerrojo y, esperar que el mundo pase. Ahí esta nuestra elección. En nuestro trabajo de gestión vemos la imperiosa obligación de estimular la actitud de investigar sin sentir que hay que hacerlo por una obligación: hay que hacerlo por degustarla, por sentir alegría y felicidad ante el hecho concreto. Sentir que enseñar y aprender son un placer y que estas dos acciones son parte fundamental de la vida. El desarrollo de una actitud investigativa, de un proceder científico se origina, entre otros elementos, primordialmente en el aula. El docente y el investigador tienen un arma invaluable: la tecnología, una herramienta indispensable - no un fin-que ayuda en el trasegar en pos de la verdad. El acto de formar, de informar, de llevar al otro, de ir con el otro, de indicarle el camino, de andar con el otro, de vencer obstáculos, de trasegar en pos de la verdad, fundamenta nuestro trabajo, le da vida al proceso investigativo, docente y proyectivo.

En este momento recuerdo que en uno de mis primeros artículos, titulado ¿Y para qué leer? (Parra, 1994, 45), empecé a cuestionar el eterno problema que tenemos los pedagogos y que se agudiza día tras día, sintetizado en frases sencillas que encierran un mundo problemático: "Esos muchachos que entran a la Universidad no tienen ni idea de la lectura" -"No sé que pasa pero cuando entro al aula de clase mis estudiantes no han leído lo que les puse" - "Los mandé a buscar un tema muy sencillo y no fueron capaces de encontrar lo que quería", e infinidad de comentarios alrededor de la lec- tura, luego de la escritura y, ahora, de la investigación. Y aquí se agudiza la cuestión, porque para investigar, necesariamente, hay que introducirse en la red, con el problema complejo que significa meterse en un objeto lleno de huecos, porque esa es la red, en su sentido más estricto: "un aparejo que sirve para cazar o pescar", un instrumento que caza, que apunta a una infinidad de posibilidades y logra que algunas de ellas queden ahí; un tramado elemental, un tejido de mallas. En informática, el concepto de red connota un sistema de computadores o de aparatos, en la mayoría de las ocasiones separados por el tiempo y la distancia, pero conectados o unidos por las múltiples formas y oportunidades que brinda el lenguaje y la tecnología de las telecomunicaciones. En nuestro caso específico se refiere a un conjunto de investigadores individuales o agrupados en pequeños círculos que se unen a otros, interrelacionados por propósitos comunes, un universo de educadores enlazados por formas de comunicación que probablemente incomunican y sólo son relevantes en cuanto tocan, no nuestros intereses, sino mi interés, lo que yo busco.

\section{Investigación y narrativa}

Muchos siglos antes de la aparición del mundo en línea y de los múltiples significados, investigaciones y escritos acerca del fenómeno de la comunicación interactiva universal, fenómeno que a finales del siglo XX volvió a resquebrajar la historia, un icono de la literatura, Homero, mostró en una de sus obras, La Odisea, lo que significa navegar sin rumbo, adentrarse en un mar caótico gobernado por el azar y el destino inexorable que nos puede conducir a cualquier parte, el mismo caos que encuentra un docente, un investigador o un navegante desprevenido al adentrarse en la web o en la red o en la línea-los especialistas en informática diferencian estos términos con otras formas significativas más complejas y más exactas-. Al respecto manifiesto que adentrarse en la red es, exactamente lo que connota su primer significado, introducirse en un objeto lleno de huecos, con infinitas posibilidades de salirse de la misma y con igualdad de posibilidades para pescar algo. 
No podría olvidar otro significado que tiene la red y es el de ardid o trampa. No por azar, o, tal vez sí, Ulises, el héroe central de La Odisea, es el rey de los ardides, el navegante que se adentra en el caos que le organiza Poseidón; es el mismo personaje que en La lliada logró vencer la resistencia de los troyanos al introducir en la ciudad inexpugnable su caballo de Troya. El ardid del navegante consiste en echar bien la red, en pescar, en sumergirse en la línea con propósitos bien definidos.

Hoy podemos apreciar organizaciones complejas que nos brindan servicios muy sistematizados y posibilidades infinitas de acceso a la información. Uno de los insignes escritores de habla hispana, Jorge Luis Borges, consideró siempre que su felicidad más grande era morir y encontrar que el paraíso era una biblioteca infinita. Si seguimos al pie de la letra su consideración de la felicidad, podríamos decir, sin temores, que el Edén se localiza aquí, en medio de nosotros, por lo menos el paraíso de los datos incontables, unido, paradójicamente, al infierno de los mismos, porque el cúmulo informativo que uno puede percibir no tiene parangón y, ahí está la tarea del docente, ahí se encuentra la labor del investigador, ahí está la expectativa del alumno.

Como estudiante, como asistente investigador, como aprendiz, me encuentro a las puertas informativas y el profesor, el tutor, es exactamente un acompañante, un guía. En este punto vuelvo a la metáfora, a la literatura, y miro en el espejo del tiempo a Virgilio, introducido por Dante en la Divina Comedia que, en palabras de los expertos, sólo era Comedia (el término de Divina llegó posteriormente). Virgilio va a ser el conductor, el mediador, el introductor, el símbolo del docente, del tutor, del facilitador, en su expresión más cercana a la figura que hoy se quiere tener para los profesores y para los modelos pedagógicos presentes en este mundo atiborrado de información. Al igual que Dante, nos vamos a "encontrar en mitad de una selva oscura" "2, en una clara alegoría a la confusión en la cual se puede hallar un investigador frente a la información, de cara a otro mundo, un investigador, solo, perdido, aislado (un peligro enorme, un reto para el aprendizaje autónomo, para el aprendizaje colaborativo y para cualquier forma de abordaje del conocimiento y de la formación). No en vano ni por azar, la Divina Comedia se encuentra escrita en primera persona, haciendo del viaje un compromiso íntimo, donde el personaje, en este caso el maestro, afronta y confronta, viaja y hace suyo el proceso, el itinerario:

Conocemos profundamente a Dante por un hecho que fue señalado por Paul Groussac: porque la Comedia está escrita en primera persona. No es un mero artificio gramatical, no significa decir "vi" en lugar de "vieron" o de "fue". Significa algo más, significa que Dante es uno de los personajes de la Comedia (Borges, 1980, 18).

Tan asustados como Dante frente al dintel ${ }^{3}$ de la puerta que transporta al otro mundo, nos vamos a encontrar los docentes, los investigadores y los estudiantes al dar vuelta al pestillo que nos introduce en un universo lleno de posibilidades infinitas, el orbe innombrable de la era informática.

\section{Los modelos, los medios y las mediaciones}

Hace unos pocos años se hablaba de una educación para toda la vida como de una meta o una quimera que

"En medio del camino de nuestra vida, me encontré en una selva oscura, por haberme apartado de la buena senda. Difícil es decir cómo era aquella salvaje selva, áspera y tupida, cuyo recuerdo evoca su pavor. Tan amargo pavor, que de la muerte poco se distingue; pero voy a contar otras cosas que vi en ella, para tratar del bien que en ella encontré" (Dante, 1971, 19) El cúmulo de información semejante al mundo atiborrado de experiencias se encuentra claramente planteado en el Canto I de la Divina Comedia e invita a la reflexión sobre el dilema que se le presenta a un docente o a un investigador a través de la metáfora de iniciación del Poema.

3 La inscripción famosa del poema de Dante ha trascendido el escrito y se ha introducido en la mente y la concepción de mundo a través del tiempo. Múltiples metáforas hacen alusión a su mensaje, lo mismo que el significado escueto se encuentra grabado en tumbas y cementerios incontables, trayendo a colación la introducción en otro mundo, en un caos eterno: "Por mí se va a la ciudad del llanto, por mí se va hacia el dolor eterno, por mi se va hacia la perdida gente. La justicia movió a mi autor supremo. Hiciéronme la potestad divina, la suma sabiduría y el amor primero. Antes de mí no hubo cosas creadas, sino eternas, y yo terrenamente permanezco. Abandonad toda esperanza, los que aquí entráis" (Dante, 1971, 26). 
debía buscarse. Hoy, en los albores del siglo XXI, el concepto no es un ideal, es una necesidad. El paradigma que enmarcaba la existencia humana, desde un niño que aprendía, un adolescente que consolidaba el aprendizaje y un joven que se graduaba y salía en pos de su trabajo, asegurando, cuando lograba situarse, un puesto en la vida, ha cambiado. La transformación del horizonte la dio un pequeño bit que hizo volcar toda perspectiva hacia el conocimiento y el avance tecnológico. Sin ninguna duda, la relación didáctica-aprendizaje-trabajo-vida tiene un sustrato elemental que es el conocimiento. Ningún profesional, en nuestro caso ningún docente o investigador, puede dar por sentado que su ciclo ya acabó, que el haberse titulado y haber trabajado duramente asegura su futuro. Si el profesional no se encuentra constantemente relacionado con el medio, si no actualiza su bagaje de conocimiento y si no está a la vanguardia en los cambios que suscita el avance tecnológico quedará fuera del círculo de aprendizaje y, por consiguiente, sus procesos didácticos se encontrarán desactualizados y su capacidad investigativa estará cuestionada.

Pensamos que una reflexión sobre las nuevas tecnologías y su influencia en las tendencias educativas actuales nos brindan elementos para lanzarnos a la aventura pedagógica, al albur del conocimiento, y creemos que este punto de partida es acertado. Supongamos por un momento que Simon Murison-Bowie, quien ha sido Director de Aprendizaje Interactivo de Oxford, en Oxford University Press, y un defensor incansable de los elementos tecnológicos como suscitadores del aprendizaje a distancia permanente -en el transcurso de la vida, tiene razón y que sus investigaciones y aportes nos hacen pensar que no puede haber un aquí y un ahora que determinen la educación. Es más, la respuesta cientifico-técnica varía constante y velozmente; en este momento en el que estamos interactuando y reflexionando acerca de la influencia tecnológica, en el mundo entero se están conectando millones de personas y se intercambian los más variados mensajes, algunos crean- do conocimiento, otros adaptándolo y unos más aprendiendo de manera diversa y con medios y mediaciones que escapan a nuestro alcance:

Al considerar el impacto de las redes digitales, es tiempo de llevar el argumento a las interrogantes del "qué" y del "cómo". ¿ ¿Cuál es el impacto causado sobre quése aprende y cómo se aprende? Olvidando la imperativa realidad por un momento, si la naturaleza de lo que los educandos aprenden y la de los métodos mediante los cuales aprenden no se cambian en términos materiales y de beneficios, entonces, a pesar de la conveniencia de cuándo y dónde, debemos olvidarnos de la tecnología. Si el medio no afecta el mensaje, entonces olvidemos el medio; sería mejor distribuir el gasto educativo de otras maneras. No obstante, debido a que la tecnología puede y causa impacto sobre aquello que aprendemos y sobre cómo lo aprendemos es que debemos permitir que la tecnología permanezca en la ecuación (Murison-Bowie, 2001, 143) ${ }^{4}$.

\section{Informática, narrativa y aprendizaje}

Volviendo a Dante y ya introducidos en el caótico mundo de la informática, empezamos a cuestionar y a ser cuestionados. No oiremos los suspiros ni las quejas de los que vivieron sin alabanzas ni vituperios, de los que no son merecedores del Cielo ni del Infierno, que escucharon Dante y Virgilio, pero sí estaremos enfrentados a las preguntas y a los temores de los estudiantes, docentes e investigadores que dudan y se interrogan frente a los adelantos tecnológicos: ¿cómo elegir un docente virtual?, zun docente presencial puede ser un docente virtual?, ¿cuál es el rol del estudiante y cuál el de la institución?, ¿ los nuevos medios reemplazarán el papel del profesor?, ¿qué le pueden aportar unos datos fríos y un cúmulo informativo a una investigación?, ipuedo enfrentarme al estudio y a la investigación sin ayuda, sin intercambio?... Una transformación de esta naturaleza no tiene sentido: para qué las nuevas tecnologías si lo que existe funciona bien y así debe quedarse...

$4 \quad$ LEER, Anne. La visión de los líderes en la era digital. México: Pearson 2001. 
Los anteriores cuestionamientos unidos a juicios, mitos, prejuicios y realidades, nos van dando una idea del camino por el cual transitamos, el áspero pero esperanzador sendero de Dante. Creemos que la tarea más ardua en este punto es seleccionar la tecnología y los sistemas más apropiados para nuestras necesidades, paralelamente a las formas esenciales de aprendizaje, con el horizonte claro y quizás lejano de la producción del conocimiento.

Los sistemas cambian constantemente, las tecnologías de la información y la comunicación, TIC, varían. Un investigador o un docente, de cualquier lugar, inmerso en cualquier enfoque o tendencia, debe distinguir algunos elementos mínimos comunes, desde la unidad más pequeña que un computador puede procesar: bit, hasta el dispositivo instruccional electrónico para un computador que se puede ejecutar en un hardware: el software; debe tener conciencia de la existencia de los mecanismos sencillos que tienen una relación determinante con el proceso de búsqueda, con la razón básica de la investigación: con la pregunta; por ejemplo, que existen fuentes especializadas en la búsqueda, que hay métodos sencillos que agilizan el proceso en la web, que se puede utilizar indistintamente el plural en la búsqueda, que algún signo (+) nos hace más ágil el acercamiento a la respuesta 0 , de una manera más compleja, que en nuestro proceso investigativo podemos crear webs, nidos de investigación y aprendizaje colectivo; en este punto, cada vez más, las empresas tecnológicas nos brindan mayores herramientas y se preocupan, desde sus intereses particulares, por abrir el campo investigativo, las posibilidades de información y de avance científico que pueden ser utilizadas por los docentes de una manera eficaz.

Algunos de los lectores se encuentran familiarizados con lo que estamos diciendo, para otros estaremos hablando en un idioma extranjero. Precisamente ése es el mundo que encontramos con nuestros estudiantes, profesores e investigadores, un universo múltiple, lleno de diversas perspectivas. Similar al dantesco universo, saltando los nueve círculos del infierno podemos adentrarnos sin temores en el purgatorio, sabiendo que es "el monte más alto de cuantos hacia el Firmamento se elevan sobre las aguas". Esta comparación puede servirnos para ver nuestro enfrentamiento a las tecnologías y, por supuesto, a la incidencia de las mismas en el proceso pedagógico. Son innumerables las amenazas que asaltan a los docentes - un poco menos a los investigadores-al enfrentar las nuevas tecnologías, miedos que, salidos de la oscuridad, nos recuerdan los temores infantiles cuando no queríamos dormir a oscuras o cuando sufríamos por el temor de los monstruos que podían acompañar nuestros sueños. En nuestro correlato empieza a aparecer un elemento determinante en la subida a la montaña del Purgatorio: Virgilio, el tutor, el acompañante, el facilitador:

Entonces mi guía me cogió, y con palabras, gestos y señas me indicó que doblase la rodilla con reverencia y bajase los ojos (Dante, El Purgatorio, Canto I, p. 140).

La búsqueda de lo esencial en el aprendizaje connota diversos acercamientos. De manera similar a como los alquimistas medievales querían descubrir la piedra filosofal que transformara el metal en oro o los simbolistas indagaban por un símbolo integrador o una palabra que sintetizara el universo, también algunas religiones buscan su origen en el verbo que llene la existencia y la educación pretende hallar la fórmula mágica que responda a las necesidades de aprendizaje y de autogestión del conocimiento. Sin mayores dificultades, podemos encontrar la propuesta de diversos métodos que tratan de mostrar la facilidad para apropiarse de la realidad o por lo menos para acercarse a ella. Durante mucho tiempo la mnemotecnia fue una clave para memorizar y se buscó, a través de este método, la mejor forma de grabar datos, números, frases, textos, colores, objetos, en fin. Acercamientos que, en últimas, siempre vuelven a una operación elemental que dicta el cerebro: la asociación.

En el artículo Mnemotecnia de la palabra clave: efectividad en el aprendizaje, Ángeles Amor y María Ángeles González de la Universidade da Coruña y Alfredo Campos de la Universidad de Santiago de Compostela tra- 
tan de hallar la significación de la palabra clave en el aprendizaje, basados en diversas investigaciones, pretendiendo acercarse a una explicación de la influencia del método mnemotécnico en la aprehensión de idiomas extranjeros y de otras formas de conocimiento. Aludiendo a dos autores reconocidos en este ámbito (Atkinson y Raugh) recuerdan uno de los criterios claves en el aprendizaje mnemotécnico que va a ser de mucha ayuda en los procesos de utilización de las nuevas técnicas de comunicación e información: "la imagen interactiva recordable". El criterio recordado considera que la palabra clave en el proceso mnemotécnico "debe permitir elaborar una imagen interactiva recordable, una vez puesta en relación con la traducción de la palabra no familiar, por este motivo se aconseja la elección de las palabras concretas sobre las abstractas" (Amor y María, González, y Campos, 2000)5.

\section{Lenguaje, aprendizaje y TIC}

Hemos querido traer a colación la palabra clave, dado que en el mundo de las TIC y en su relación más estrecha con la docencia y la investigación esta noción constituye el carburante de los llamados motores de búsqueda, ¿cuál docente, investigador o estudiante no ha utilizado en estos tiempos de las nuevas tecnologías un motor de búsqueda para el encuentro de una palabra clave? Lo terminamos de poner en práctica, acabamos de buscar el vocablo griego referente a la memoria, a la mnemosis, a la mnemotecnia y encontramos varias direcciones, una de ellas nos llevó al artículo anteriormente citado. Los motores funcionan de diversas maneras y, naturalmente, cubren toda la web. Uno de los primeros motores de búsqueda fue Altavista, con su facilidad para las noticias, los diversos temas y las consultas con palabras clave. Existen numerosos motores de búsqueda, pero es quizás Google el que ha desbor- dado las expectativas e inclusive ha puesto la información y el aprendizaje a la mano. Este instrumento de exploración ha pasado a constituirse en una herramienta didáctica y de aprendizaje determinante y en un componente clave en los procesos de investigación, suministrando desde las definiciones más elementales, hasta las conexiones con temas sumamente complejos. Cada día se pueden observar los avances incontenibles del monstruo informático que brinda múltiples herramientas para el aprendizaje autónomo, la autogestión del conocimiento, la puesta en práctica del aprendizaje interactivo, el fomento del aprendizaje creativo y las posibilidades de asegurar, dentro de un proceso de enseñanza-aprendizaje, las competencias cognitivas, comunicativas e investigativas.

En la red se encuentra todo, a todas horas, para todos los gustos, una puerta abierta a una gama infinita de posibilidades. Desde esta perspectiva abrumadora, los docentes y los investigadores tenemos que buscar y rebuscar diversas formas de apropiación racional de los contenidos y la información que nos apabullan. Constantemente suelen encontrarse advertencias sobre la utilización errada que se le puede dar a la red. Los avisos sobre la navegación segura y sobre el mal uso que se le puede dar a la información puesta en las autopistas se volvieron un pan cotidiano. En las tareas y en las investigaciones nos vemos abocados al proceso común denominado "corte y pegue" que inclusive trasciende el abordaje pedagógico y se convierte en un problema ético que no solamente está en el ámbito educativo sino en todos los campos sociales. Sabemos y somos conscientes de que el hecho de encontrar la información y "bajarla" no es suficiente. Nuestra tarea, como en la recordada serie de "Misión imposible" ${ }^{6}$, si decidimos aceptarla, y de hecho debemos hacerlo, es no solamente tener un acercamiento a las TIC, sino manejar

http//fs-morente.filos.ucm.es/Publicaciones/Iberpsicología/congreso/congreso.htm. Consultada: junio 27 de 2006.

6 A finales de la década de 1970 una serie televisiva llamada "Misión imposible" impactó al mundo por su novedosa versión, en la cual unos agentes que simbolizaban, cada uno, una parte del ser humano: inteligencia, fuerza, belleza, ciencia, tecnología, arte y trabajo individual y en equipo, trasladó a los televidentes diversas formas de ver el mundo. Una de sus frases favoritas: "Su misión Jim, si decide aceptarla, será..." se volvió un lema que recorrió diversas culturas. A finales del siglo XX y comienzos del XXI, la serie fue llevada al cine y se hicieron tres versiones de gran impacto, tratando de rescatar el mensaje que tenía la serie televisiva. 
algunos elementos que nos den facultades para poder indicar, guiar y facilitar un proceso mínimo de acercamiento crítico a la información, para que los estudiantes y nuestros colegas docentes e investigadores podamos aproximarnos a la información con un pie puesto en el análisis y la evaluación de lo encontrado y otro en la posibilidad de su utilización ética.

Durante mucho tiempo se ha hablado de la dosificación del aprendizaje, de dividir las unidades en sus partes constitutivas, de dar clases, de semestralizar, de periodizar $y$, de pronto, aparece una posibilidad que brinda la información de una manera distinta, se puede tener lo que uno quiera sin horarios, sin restricciones, sin días determinados, sin nadie que toque la campana, sin escuelas, ni normas, ni maestros y, lo más grave, sin recreo. Esto último parecería un chiste de mal gusto, pero es una verdad. Cortar un rito o ponerle punto final a un elemento determinante en el cual se socializa, se comparte, se juega, puede ser contraproducente. Los visionarios de las nuevas tecnologías lo han visto así y están tratando de introducir el juego y la incertidumbre, el divertimento, la emoción y un sinnúmero de elementos que acompañan la información para que ésta no se pierda en una fría y desordenada comunicación. Otra vez se vuelve a la dosificación, no de la misma manera que fue $y$ es, dentro de un formato tradicional pedagógico, pero sí dentro de una lógica, movida por lo menos por los procesos mentales que hacen que el ser humano cambie de objetivo, fije su atención, resalte su aprendizaje basado en una comprensión espaciotemporal determinada.

Desde este horizonte, suele acudirse a los llamados bloques de información que brindan determinados contenidos, a las ayudas "didácticas" o publicitarias que enfocan la información, a los llamados blogsy a los diseños tecnológicos variados que se adaptan a una sociedad de rápidos contrastes donde los cambios son casi instantáneos.
Nos afanamos por ver la información en bloques rápidos, olvidando que existe una cultura, un ambiente que invita a ver imágenes sincrónicas, antes que diacrónicas. Tampoco podemos dejar de lado la experiencia que nos indica que la lectura de temas largos en la pantalla es muy complicada y tediosa -por lo menos ésta es una de las inquietudes de Bill Gates, quien prefiere leer un tema largo en un libro antes que enfrentarlo largo tiempo en una pantalla-. Las nuevas formas expresivas nos lanzan a lenguajes rápidos y directos, tanto que se suelen encontrar en el lenguaje comunicativo de nuestros adolescentes palabras incompletas, frases que se han vuelto cotidianas que economizan y que quizás matan el encanto del lenguaje o, por lo menos, la magia de las frases y los párrafos que nosotros conocemos, pintando de otro color la ortografía, la redacción, la investigación, la forma de aprender y de comunicarse.

Observemos el siguiente ejemplo de un comunicado, en el cual no se tiene en cuenta el orden lógico de las letras:

\section{El gtao se ecsapa ${ }^{7}$}

Tneog en la mneet aglo dsagaarablbe. Ssoephco qeu utsde sbae qéu es. ¿Preo sbae utsde qeu yo ssoephco qeu utsde sbae? Yo cero qeu tla vze sí, preo no etsyo sgeruo. Cbane mcuahs ddusa... Aglnuso pneasimneots es mjero epxeraslros con plabaras.

Igual que con este ejemplo sencillo, se encuentran otros ejemplos derivados de las formas de comunicación que establecen nuestros estudiantes y los mismos docentes e investigadores: porfa o pofa o pof o pf, en lugar de "por favor", y así podríamos hacer un listado extenso con estas nuevas formas de comunicar. Los mensajes no se dan solamente con palabras, las imágenes visuales cobran sentido y, en muchas ocasiones, desbordan las formas verbales, se mezclan con ellas, las eliminan. Los docentes y los investigadores tenemos que estar

El gato se escapa Tengo en la mente algo desagradable. Sospecho que usted sabe qué es. ¿Pero sabe usted que yo sospecho que usted sabe? Yo creo que tal vez sí, pero no estoy seguro. Caben muchas dudas... Algunos pensamientos es mejor expresarlos con palabras. (NalebuffBranderburger, 2005). 
atentos a estas maneras diversas de comunicación y de relación con el medio.

Si antes nos maravillábamos con lenguajes plasmados en bloques de tiras cómicas como Mafalda, Benitín y Eneas, Calvin y Hobbesy Olafo el amargado, entre otras muchas, hoy tenemos que visualizar modernos lenguajes plenos de técnicas visuales, colores, adelantos científico técnicos e infinitas posibilidades de interacción e inclusive de modificación del mensaje. Por ahora, recordemos a Olafo, tira cómica creada por Richard Browne en 1973: Hägar the horrible, conocida en nuestro idioma como Olafo el amargado u Olafo el vikingo o simplemente Olafo. Su personaje principal representa la interacción del pasado con el futuro, los elementos modernos entremezclados con el pensamiento tradicional, el juego del lenguaje en su máxima expresión, unas posibilidades didácticas y artísticas que no quieren dejarse avasallar por los modernos tratamientos. Exactamente lo que nos ocurre a los docentes y a los investigadores actuales en esta etapa de transición, en la cual nos enfrentamos a los adelantos científico-técnicos sin dejarnos acomplejar por los modernos sistemas que quieren apropiarse del mundo y de la realidad: un reto a nuestra creatividad y a nuestra forma de pensar y de sentir. La relación de Olafo, un aventurero vikingo, con el mundo está determinada por su entorno familiar, por la formación de sus hijos, por el imperante de su ataque simbólico a castillos inexpugnables, por la visita del recaudador de impuestos y por la atención al médico, dentro de una batalla eterna, constante, realista y mágica. Eddie, el afortunado, contrasta con la visión "realista" de Olafo y plantea alternativas que desde su ingenuidad suenan muy lógicas. Helga, la mujer de Olafo, siempre pendiente del ingenuo y audaz trotamundos, nos devuelve a los docentes las tareas que pueden generarse en el hogar y en el entorno familiar, recordándonos siempre que no estamos solos en el mundo. Los requerimientos pedagógicos se encuentran reflejados en Hamlet, hijo de Olafo, un símbolo del futuro y de las amplias posibilidades que nos puede deparar el desarrollo pedagógico e investigativo. Honi, una niña, aparentemente sin rumbo y sin metas concretas, puede definir el destino de la humanidad en cualquier momento caminando por una delgada línea entre el saber y el no saber. Los otros personajes: el pato Kvack y el perro Snert, son los aprendices permanentes que encuentran realidades diversas en cada ocasión, simbolizan la posibilidad de escape y de creatividad, de poner en funcionamiento una gama de alternativas de ejemplo, perseverancia y progreso que Ilaman la atención de los lectores y seguidores de estas opciones de lenguaje didáctico, pedagógico, investigativo y de divertimento que propuso Richard (Dick) Browne y ahora su heredero de pensamiento (Chris Browne).

Más allá del lenguaje del comic, del lenguaje científico, del lenguaje artístico, e inclusive del metalenguaje educativo, la tecnología desbordaría los desarrollos didácticos en el aula de clase y, por supuesto, los métodos investigativos. La teleinformática ha dado un vuelco sorprendente en el ámbito pedagógico y ha hecho de las computadoras un apoyo cotidiano, esencial en la elaboración de materiales didácticos, comunicación simultánea de voz, multiplicidad de imágenes, datos, videos. Prácticamente no podemos vivir sin el apoyo de internet, sin la consulta diaria del correo electrónico, sin el envío y la recepción de información en las más diversas, sencillas y complicadas formas. Variadas investigaciones hacen referencia a la invasión del lenguaje tecnológico en el diario vivir y en el ámbito profesional, en todas las dimensiones. Se habla de consultas en internet hechas desde la oficina, la alcoba, el patio de la casa, el parque, el baño y hasta desde el más íntimo y secreto rincón de la existencia.

Los avances y el acelerado desarrollo tecnológico desbordan los pronósticos más insólitos. La vida y el ejemplo de los grandes revolucionarios de la ciencia y la tecnología se encuentran al alcance de la mano tanto como sus invenciones y sus aportes. En estos últimos días circuló la noticia del retiro del mundo empresarial de uno de los creadores más grandes del siglo XX, Bill Gates. Nadie puede negar que el Outlook y el Word, entre otros íconos tecnológicos, constituyen el pan diario de los profesores e investigadores, aparte de los innumerables productos científicos que se inventan y reinventan permanentemente y que alimentan los mar- 
cos diarios de la implementación de las tecnologías en la didáctica, en la investigación, la ciencia, el arte, la industria y el vivir cotidiano.

Bill Gates podría catalogarse como un enseñador de una nueva didáctica, como el iniciador de otras formas de acceso al conocimiento y a su gestión, como el propulsor de alternativas distintas de investigación. No sólo por él y su gestión como persona e investigador, sino por el monstruo que creó: Ios aportes a las TIC desbordan cualquier planeamiento didáctico e influyen profundamente en los ámbitos del aprendizaje y la investigación. Cualquier elemento informativo, formativo y creativo tiene que ver con las TIC, no hay escapatoria, quiéranlo quienes trabajan en el avance de las tecnologías o no tengan esa intención, querámoslo o no nosotros mismos ${ }^{8}$.

Los nuevos conceptos de aprendizaje significativo, colaborativo, de autogestión y de autoaprendizaje independiente tienen como referente, de una u otra forma, las nuevas alternativas tecnológicas que día tras día invaden el ámbito pedagógico. La mayor compañía mundial de software estará sin cabeza, no quiere decir esto que el auge y el impacto de las nuevas tecnologías se estancará, quizás tendrá un nuevo rumbo. Windows, Word, Outlook e Internet Explorer seguirán haciendo parte de nuestros paquetes educativos, por lo menos por un tiempo. Entre tanto, dentro de los caminos tecnológicos proseguirá la búsqueda de diversas formas pedagógicas de acceso al conocimiento, dentro del riesgo de lo inesperado, del juego de la enseñanza y el aprendizaje, de la investigación, del diario vivir.

No por azar se puede deducir que la importancia del aprendizaje significativo favorece el análisis, el aprendi- zaje de hechos, procedimientos, conceptos y actitudes, un aprendizaje que se inserta en el mundo y encuentra significación. Las nuevas tecnologías favorecen estas formas de aprehender la realidad, de hacerla nuestra, pero vale la pena adentrarnos en la posibilidad de plantear alternativas, de visualizar propuestas formativas e investigativas, nuevas formas didácticas, las cuales se generan en determinado contexto y obedecen a un marco espacio-temporal determinado. El aquí y el ahora juegan un papel importante, primordial. El juego requiere que se calcule, no necesariamente si se va a ganar, pero sí cuánto se requiere y qué se arriesga, cuestionándonos no sólo por lo que perseguimos, por la forma de lograr nuestras metas, por los medios para alcanzar nuestros propósitos sino también acerca de quiénes entramos en el juego, con quiénes jugamos y quiénes quedan afuera.

Vale la pena detenernos por unos momentos en la última cuestión. La necesidad del otro, del equipo, del grupo es tan apremiante que determina el grado de sobrevivencia y hace realidad la premisa de que nadie puede vivir solo como nadie puede investigar aisladamente. Los niños constituyen un elemento claro que ratifica esta idea, confirman que el aprendizaje supone al otro, sus intereses, expectativas, metas, anhelos y sueños. La colaboración, la significación, la resignificación, el signo y el símbolo, la ciencia y el arte cobran sentido y conforman un sustrato educativo que supone un avance permanente, un preguntarse constantemente, una búsqueda constante de la verdad. El juego de las nuevas tecnologías queda planteado y de nosotros depende la respuesta y el papel que desempeñemos desde adentro o desde afuera del mismo.

Al mostrar a Bill Gates como ejemplo de revolucionario de la ciencia, la tecnología y la informática no se pretende desconocer la influencia ni el aporte de otros creadores, críticos, descubridores de la tecnología y de diversos instrumentos tecnológicos. Se podría citar a otro ícono tecnológico: Richard Matthew Stallman, una de las figuras revolucionarias opuestas a la privatización y al manejo particular y exclusivo del software. Sus creaciones apuntan a un movimiento de software libre y a un método que lleve a la administración, el manejo y la transformación del software sin licencia y con plena libertad. De amplio reconocimiento en el mundo entero, "inventó el concepto de copyleft, el cual se utilizó en la Licencia Pública General GNU (conocida generalmente como la "GPL») en 1989". (www.stallman.org/, http:// enciclopedia.us.es/index.php/Richard_Stallman, www.colombialink.com/01_INDEX/index_tecnologia/gurus/stallman.html) 


\section{Ciencia, lenguaje y tecnología}

Ahora, rememoremos una conversación de Carl Sagan? un investigador $y$ formador por excelencia que simboliza la combinación entre lo exacto y lo metafórico, entre la ciencia y el lenguaje común, entre lo racional y lo simbólico. Sagan en diálogo con su abuelo, contado por el mismo científico en el Prefacio a la obra La conexión cósmica, manifiesta que:

Cuando yo tenía doce años, mi abuelo me preguntó mediante un traductor, pues nunca había aprendido bien el inglés-qué quería ser cuando fuese mayor. Le respondí que "astrónomo", palabra que, al cabo de unos momentos le tradujeron. "Si-respondió-, pero icómo te ganarás la vida?" (Sagan, 1985, 7).

Casi que podríamos hacernos la misma pregunta y tratar de respondernos como maestros, con nuestra perspectiva y nuestra visión de futuro. También se nos podría cuestionar, de manera similar, acerca de la forma de sobrevivir, problema que se acrecentaría si manifestáramos que, aparte de ser docentes, quisiéramos ser investigadores y que, junto a ello, pretendiéramos utilizar las novedades tecnológicas y los adelantos científicos que día tras día sobrepasan los ámbitos de la ciencia y la tecnología y se incrustan no sólo en el campo educativo sino en la vida personal.

Los avances tecnológicos no se adentran exclusivamente en la ciencia misma y en las diversas profesiones sino que entran a formar parte de la vida personal: el celular, por ejemplo, pasó de ser un instrumento útil para la comunicación interpersonal a ser una extensión del cuerpo y una parte más de nuestra cotidianidad. En los salones de clase, en las conferencias y, en general, en los eventos públicos es común oír, antes que todo: "por favor apaguen sus aparatos tecnológicos, apártense del iPod y, de manera especial, no interrumpan nuestra conversación o conferencia o taller con sus celulares".

Siguiendo con el ejemplo, podemos apreciar que nuestros estudiantes se preocupan porque el panel de navegación de su iPod no abarca lo suficiente o porque en algunos sitios la conexión se pierde, porque la interfaz es confusa o porque las opciones de carga y descarga de canciones no son suficientes.

\section{La inventiva y la ficción}

Las muestras de la incursión de diversas tecnologías son abrumadoras y cuestionadoras; pero, volvamos los ojos a nuestro campo pedagógico- investigativo y recordemos a Isaac Asimov ${ }^{10}$, un científico y literato (hermosa combinación de profesiones) que, junto a Sagan y Feynmann" ${ }^{11}$ dedicó toda su vida a tratar de poner al alcance del lenguaje común, de los niños y de las personas sencillas, los postulados de la ciencia y de la explicación de la realidad, desde un lenguaje que rebasara lo preciso y que sin perderlo fuera fácilmente entendido. De una u otra manera, sentando las bases de la introducción de la ciencia y la tecnología en la labor pedagógica e investigativa de los educadores.

Hablar de la investigación a través de las nuevas tecnologías también es darle razón a los postulados de la

9 Carl Sagan, profesor de Astronomía y Ciencias espaciales, científico especializado en resolver misterios como el de la alta temperatura de Venus, entre otros muchos, fue un estudioso del cerebro y sus alcances, autor de 30 libros, galardonado con múltiples premios, tuvo un gran interés por bajar la ciencia de su pedestal y dejarla al alcance de la gente común, de los niños. Su obra cosmos es conocida en el mundo entero como un ejemplo de lenguaje científico trabajado en lenguaje sencillo.

10 Isaac Asimov es un bioquímico que se constituye en otro los grandes escritores que se une a Sagan y a Feynman al tratar de llevar la ciencia al lenguaje pedagógico, artístico y cotidiano. Escribió y editó más de 500 volúmenes de ciencia-ficción y de carácter científico y 90.000 cartas. Se le conoce como uno de los más sobresalientes representantes de la ciencia-ficción. Su obra Fundación y todos los escritos sobre robots muestran un gran conocimiento y una visión futurista muy clara. Su lenguaje didáctico facilita la comprensión de la realidad.

" Richard P. Feynmann, uno de los más ilustres científicos del siglo XX, resume algunos ensayos, entrevistas y propuestas en "El placer de descubrir", en los cuales trata de mostrar desde la belleza de una simple flor, hasta las posibilidades de los complejos computadores del futuro, paseándose siempre por momentos cuestionantes, por preguntas científicas sobre la esencia misma de la física y la ciencia, las cuales siempre quiso que estuvieran a la mano de sus estudiantes y de la gente común y corriente. 
ciencia ficción que, poco a poco, se hacen realidad. Hacia la mitad del siglo XX fue conocido en el mundo de la literatura de ciencia ficción uno de los cuentos más cuestionadores del futuro de la educación "Lo bien que se lo pasaban" del escritor Isaac Asimov. El cuento llama la atención sobre la incursión de la ciencia y la tecnología en la pedagogía. En este punto, es interesante comparar el momento de la publicación con los descubrimientos y adelantos contemporáneos a la misma. El mismo año de la publicación del cuento (1951) se inventó el computador UNIVAC I, calculado para una vida activa de doce años con trabajo permanente de 24 horas al día. Cinco años atrás, en 1946, se había creado el primer computador, formalmente hablando, fruto del proyecto ENIAC (Electronic Numerical Integrator and Calculator), pero todavía no se tenía en mente el desarrollo de la informática, ni siquiera la primera generación de computadores que en 1959 hizo que se hablara de lenguaje almacenado en tarjetas perforadas.

Podríamos ampliar el recorrido, pero por cuestión temática, y de tiempo y espacio, nombremos solamente algunos eventos significativos: en la llamada segunda generación aparecen los lenguajes de programación FORTRAN, COBOL Y BASIC (1959 a 1964). En la tercera generación, durante los cinco años siguientes, se investiga sobre la inteligencia artificial y comienzan las primeras aplicaciones del computador para administrar el conocimiento. En la década de los setenta se dispara el desarrollo de los computadores y se empieza a hablar de las redes y autopistas de la información. A finales del siglo XX y comienzos del siglo XXI, ya en la sexta generación de computadores, las nuevas tecnologías se enfocan en la robótica, la inteligencia artificial y la posibilidad de procesar conocimientos en lugar de datos. La informática se vuelve un factor determinante en la vida y el progreso humanos. Las herramientas virtuales, los desarrollos de multimedia y la tecnología se adaptan y se adoptan en todas las disciplinas. El sueño de los futurólogos es una realidad, la Primera Ola de la sociedad agraria marcada por la ocupación ha dado paso a la Tercera Ola, al universo de la información: la realidad de Alvin Tofler, que estaba a la vuelta de la esquina, nos sorprende al llegar más rápido de lo esperado.

Lo que en un principio era ciencia ficción y se esbozaba tímidamente se volvió un factor determinante. El mismo M.I.T. creado (1861) para responder al crecimiento industrial de Estados Unidos y distinguido, al principio, por sus estudios en ciencia, particularmente en ingeniería y luego en los diversos campos, centró, a finales de la década del sesenta (s. XX) la idea de crear las computadoras con el más alto índice de inteligencia, queriendo, al principio, investigar en las operaciones mentales e igualar las acciones que se desarrollaban en el cerebro humano con las operaciones de las computadoras.

Íconos de la informática, como Bill Gates cambiarían la historia y nos harían tecnodependientes ${ }^{12}$ y seres humanos para quienes la información y la sistematización van unidos a la vida y a la supervivencia. La ciencia ficción se salió de los libros y de las películas para dar paso a una realidad avasallante. Stanley Kubrick, en su célebre película 2001 Odisea en el Espacio, siembra la duda y la alerta al hablar de un computador capaz de pilotear una nave espacial y dejar entrever un posible paso intermedio evolutivo entre el hombre y la máquina. El mismo Isaac Asimov plantea en su cuento "Satisfacción garantizada"las posibilidades de relación afectiva que se pueden generar en un robot que llega a tener

12 La influencia determinante y el poder de la tecnología se pueden constatar simplemente con la observación del medio, con un vistazo a la vida cotidiana. Diversas corrientes marcan el mundo de la vida actual en todos sus ámbitos, el educativo no puede escaparse a esta realidad. La discusión se abre y roza tópicos que antes ni siquiera se consideraban, por ejemplo, si el software debe ser propiedad de una empresa o si es propiedad colectiva. Richard M. Stallman (Congreso Mundial de Educación Superior a Distancia, Bogotá, 2006), expresa que el software es libre y que se pueden ejecutar los programas que uno quiera y como quiera, que no puede haber restricción para el estudio de fuentes, que se pueden distribuir las copias como se quiera y que se pueden publicar las versiones cambiadas, es decir, que la tecnología debe ser de útil y de libre manejo, los diccionarios y las enciclopedias como WIKIPEDIA deben ser libres. Tal vez las obras que se escapan de esta concepción son las obras de pensamiento y probablemente los artículos científicos. Queda planteada la duda y el andamiaje de los derechos de autor, de las patentes, el rol mismo del profesor, del estudiante y de la misma formación. 
emociones y sentimientos. Pero es en la primera narración mencionada de este célebre científico y escritor "Lo bien que se lo pasaban", que queremos revisar algunos conceptos, de una manera rápida.

La narración comienza cuando Margie, una niña de once años, protagonista del cuento, escribe en una de las páginas de su diario, fechada el 17 de mayo de 2155, una frase contundente y terrible, pero sumamente real: “ ¡Hoy Tommy encontró un verdadero libro" (Asimov, 1968, 9). Y prosigue el cuento:

Era un libro muy viejo. El abuelo de Margie dijo en una ocasión que, cuando era niño, su abuelo le contó que hubo un tiempo en que todos los relatos estaban escritos sobre papel.

Hojearon las páginas, que estaban amarillentas y quebradizas, y fue muy divertido el leer palabras que permanecían quietas en vez de moverse como siempre en la pantalla, como ustedes ya saben. $Y$, además, cuando giraban hacia atrás volviendo a la página de antes, tenía en ella las mismas palabras que cuando la había leído por primera vez.

-iFiu! -dijo Tommy-. iQué derroche! Supongo que cuando uno ha acabado el libro, lo tira. Por nuestra pantalla de televisión deben haber pasado un millón de libros, y aún sirve para muchos más. Yo no la tiraría.

-Igual que la mía -dijo Margie. Tenía once años, y no había visto tantos telelibros como Tommy. Él tenía trece (Asimov, 1968, 9).

Tengamos en cuenta que el cuento fue publicado en 1951, cuando la teleeducación y las plataformas de aprendizaje con las que contamos hoy en día eran un sueño, una ficción. Desde la narración empieza un cuestionamiento hacia los medios y las mediaciones educativas y por supuesto hacia los instrumentos que pueden ayudar o complementar la investigación.

- ¿Dónde lo encontraste?
-En mi casa -señaló sin mirar, pues estaba ocupado leyendo-. En el ático.

¿De qué trata?

-De la escuela.

Margie se mostró despectiva:

¿La escuela? ¿Qué puede escribirse acerca de la escuela? Yo odio la escuela.

Margie siempre odiaba la escuela, pero ahora la odiaba más que nunca. El maestro mecánico le había puesto un examen de geografía tras otro, y ella los había ido haciendo cada vez peor, hasta que su madre había agitado apesadumbrada la cabeza y mandado a buscar al inspector regional (Asimov, 1968, 10).

En este lugar de la narración aparece el sitio donde los niños aprenden. Más que un sitio es una concepción, una forma de ver la relación existente entre la niña y el aprendizaje. También surge "el maestro mecánico", aquel que se había atrevido a colocarle un examen. Todavía no sabemos si es un maestro tecnológico o si es un ser humano mecanizado por la rutina y el diario acontecer, aunque este manejo metafórico no se ajusta al estilo de Asimov.

Era un hombrecillo regordete, con rostro rojizo, y toda una caja de herramientas con cables y cuadrantes. Le sonrió, le dio una manzana y desmontó a su maestro. Margie había esperado que no lo supiera montar de nuevo, pero sí sabía y, al cabo de una hora más o menos, allí estaba de nuevo, enorme, negro y feo, con una gran pantalla en la que se mostraban las lecciones y se hacían las preguntas. Pero esto no era tan malo. Lo que ella odiaba era la ranura por la que tenía que meter los deberes y los exámenes. Siempre tenía que escribirlos con el código que le habían hecho aprender cuando tenía seis años, y el maestro mecánico calculaba su nota inmediatamente. 
El inspector había sonreído al terminar y le había dado unas palmaditas en la cabeza. Luego, le había dicho a su madre:

-Señora Jones, no era culpa de su hija, creo que el sector geográfico estaba programado un tanto rápido. Estas cosas ocurren a veces. He disminuido su velocidad al nivel medio de los diez años. En realidad los resultados totales de su progreso son bastante satisfactorios -y palmeó de nuevo la cabeza de Margie (Asimov, 1968, 10).

Aparece el inspector, mostrando una figura un tanto ridícula y utilizando un símbolo que ha sido muy trabajado en la literatura para dar a entender que se está dando un paliativo o se está engañando a la persona que recibe el presente: la manzana. Acto seguido se muestra la máquina que enseña con su gran pantalla, sus lecciones y sobre todo, algo que nunca dejará al hombre: las preguntas. Posteriormente, surge la temática más importante en la educación, especialmente en las nuevas tecnologías: la evaluación.

Margie se quedó defraudada. Había esperado que se llevasen al maestro. En una ocasión se habían llevado al maestro de Tommy durante casi un mes, porque su sector histórico se había borrado completamente.

Así que le dijo a Tommy:

- ¿Por qué iba nadie a escribir acerca de la escuela?

Tommy la contempló con una mirada de gran superioridad:

-Porque no es nuestro tipo de escuela, estúpida. Es el viejo tipo de escuela que tenían hace cientos y cientos de años - y luego añadió, pronunciando cuidadosamente la palabra-: hace siglos.

Margie se sintió ofendida.
-Bueno, no sé qué tipo de escuela tenían haca todo ese tiempo -leyó el libro sobre su hombro durante un rato, y luego dijo-: de todos modos, tenían un maestro.

-Seguro que tenían un maestro, pero no era un maestro normal. Era un hombre.

¡¿Un hombre? ¿Cómo podía un hombre ser maestro?

-Bueno, les contaba cosas a los chicos y chicas, les ponía deberes y les hacía preguntas.

-Un hombre no es lo bastante listo como para hacereso.

-Seguro que sí. Mi padre sabe tanto como mi maestro.

-No puede ser. Un hombre no puede saber tanto como un maestro.

-Te apuesto lo que quieras a que sabe tanto.

Margie no estaba dispuesta a pelearse por eso, por lo que dijo:

-Yo no querría que un desconocido viniera a mi casa a enseñarme.

Tommy lanzó alaridos de risa (Asimov, 1968, 10).

Persisto en la importancia de cada párrafo, de cada frase narrativa. De la simple pregunta acerca de porqué nadie podría escribir sobre la escuela. La concepción educativa, la percepción de aprendizaje, la comparación de sistemas, la significación, la discusión y una serie de posibilidades de debate que se originan desde estas reflexiones futuristas que hoy están en nuestras casas y en nuestras mentes. En tan corto diálogo se puede apreciar la correspondencia hombre-máquina, las relaciones familiares, las decisiones de los padres en la educación, en fin. Surge un elemento que hoy cuestiona a muchos maestros y nos hace preguntarnos: ¿será 
que las nuevas tecnologías nos desbancan?, ¿nos quitarán puestos de trabajo?, i cómo puede un hombre enseñar y aprender al mismo tiempo de la tecnología?, ¿habiendo tantas alternativas informativas, cuál es el papel del profesor?, ¿ cómo puede evaluar un docente?, ¿qué puede enseñar que no se encuentre en las nuevas y sofisticadas autopistas de la información?, iserá que un profesor "no es lo bastante listo" como dice Tommy para enseñar, crear alternativas de aprendizaje y evaluar, en un medio que está siendo "invadido" por las nuevas tecnologías? Las preguntas siguen rondando y surgirán muchas más porque la realidad está a nuestro alrededor y se encuentra plena de tecnologías diversas que pueden ayudar o trastocar los procesos pedagógicos, investigativos, didácticos y de aprendizaje, pero que definitivamente los han cambiado. Podemos decir con nuestro Premio Nobel, Gabriel García Márquez, que "Si yo hubiera tenido la computadora hace veinte años tendría el doble de libros escritos" (Rubiano, 1991, 51) o podemos expresar con el trovador castellano Jorge Manrique (s. XV) "como a nuestro parecer / cualquier tiempo pasado / fue mejor.../".

-Desde luego, no sabes nada, Margie. Los maestros no iban a casa. Tenían un edificio especial, y los niños iban allí.

¿¡Y todos los niños aprendían las mismas cosas?

-Claro, si tenían la misma edad.

-Pero mi madre dice que un maestro tiene que ser ajustado para que se adecue a la mente de cada chico o chica al que enseña, y que cada uno tiene que ser enseñado de una forma distinta.

-De cualquier modo, entonces no lo hacían así. Si no te gusta, no tienes por qué leer el libro.

-No dije que no me gustase -contestó rápidamente Margie. Quería leer acerca de aquellas raras escuelas (Asimov, 1968, 11).

\section{Un aprendizaje significativo y satisfactorio}

Hasta este punto de la narración podríamos estar observando un acalorado debate de los defensores del aprendizaje significativo, quienes, seguramente, estarían muy pendientes de la intervención en el proceso del aprendiz, de la misma manera que se vería la situación del aprendizaje en relación con las experiencias vitales de la persona que aprende. También podríamos apreciar el alcance del aprendizaje en el que intervienen diversos individuos, medios y mediaciones que pueden enriquecer el proceso o entorpecerlo, mejor, cambiarlo de perspectiva.

No habían llegado aún a la mitad cuando la madre la llamó:

-iMargie, a la escuela!

Margie alzó la vista.

-Aún no mamá.

-Ahora -le respondió la señora Jones-y probablemente también debe ser la hora de Tommy.

-¿Puedo leer un poco más el libro contigo después de la escuela? -le dijo Margie a Tommy.

-Quizá -respondió él displicente. Se marchó silbando, con el polvoriento y viejo libro bajo el brazo.

Margie entró en la habitación-escuela. Estaba situada junto a su dormitorio, y el maestro mecánico estaba conectado y esperándola.

Siempre lo estaba a la misma hora, cada día excepto los sábados y domingos, porque su madre decía que las niñas aprendían mejor si estudiaban horas fijas.

La pantalla estaba encendida, y en ella se veía: < La lección de aritmética de hoy es acerca de 
la suma de fracciones. Por favor, coloca los deberes de ayer en la rendija> (Asimov, 1968, 11).

La comparación entre dos sistemas pedagógicos se hace patente en este fragmento. La escuela no es lo que Margie había leído en el libro que narraba una forma anticuada de aprendizaje, la enseñanza mediada por aparatos sofisticados era un hecho, el progreso se encontraba a la orden del día y nadie podría cambiarlo. No había regreso, las nuevas tecnologías esperaban al discípulo. Margie debería responder a las exigencias del medio, como los estudiantes de ahora, como los investigadores que se aventuran con las diversas tecnologías, como cualquier persona que ve cambiar su futuro. Todos tenemos que responder de una u otra manera y mejor si colocamos de manera real y metafórica nuestros "deberes de aver en la rendija".

Margie Io hizo con un suspiro. Estaba pensando en las viejas escuelas que tenían cuando el abuelo era un niño. Todos los niños de todo un barrio llegaban riendo y gritando, al patio de la escuela, y se sentaban juntos en un aula, y volvían juntos a casa al final del día.

Aprendían las mismas cosas, así que podían ayudarse los unos a los otros en los deberes y comentarlos.

Y los maestros eran personas...

El maestro mecánico proyectaba en la pantalla: $<$ cuando sumamos las fracciones $1 / 2$ y $1 / 4>$...

Margie estaba pensando en lo mucho que debían haber querido los niños a sus escuelas en los viejos tiempos. Estaba pensando en lo bien que se lo pasaban (Asimov, 1968, 11).

En este último fragmento podemos apreciar la nostalgia por los procesos pedagógicos pasados, cuando aparte de los elementos cognitivos y de las habilidades y destrezas de conocimiento que el estudiante debía adquirir también había espacio para el juego y el amor, para la risa y los gritos, para la apertura y el diálogo, para el aprendizaje significativo y colaborativo, para los momentos en que se compartía, para poder ir y venir juntos, para ayudarse unos a otros, para corresponder y comentar, para ser personas, en el sentido estricto del término. ¡Qué bella enseñanza y qué profundo cuestionamiento en tan pocas palabras! Sobre todo, que los maestros eran personas y todos la pasaban muy bien.

\section{Comunicaciones y redes (Conclusiones)}

Lo anterior no es solamente una narración, es una llamada muy seria a que juguemos un papel determinante. Las nuevas tecnologías, igual que lo fueron hace pocos años los esferos y los tableros, más allá de las pizarras, constituyen unos elementos, unas herramientas útiles que no pueden rebasar su papel de instrumentos, que no pueden manejar ni determinar a su antojo la relación docente-investigador-estudiante; relación de la cual depende el futuro, nuestro futuro. Nosotros tenemos el lenguaje y el instrumento en la mano. De nosotros es la decisión, la última palabra, el destino, la supervivencia. Podemos acercarnos a las nuevas tecnologías para investigar de una manera sencilla o podemos complicar nuestro acercamiento, esa es nuestra decisión y más que nuestra decisión es nuestra opción, so pena de alejarnos del entorno y de nuestros estudiantes, semilleros, nuevos talentos, grupos de investigación. La satisfacción de podernos introducir en este mundo corre a la par de la probabilidad de alejarnos del mismo.

En cualquier proceso de aprendizaje o de investigación "mediado" se supone que deben existir redes colaborativas o, por lo menos, contactos entre los diversos intervinientes que generen situaciones de aprendizaje y climas investigativos. La implementación de las TIC en los acontecimientos diarios y a largo plazo abren los espacios para que los estudiantes y los investigadores accedan a determinada información y la administren. Tenemos aquí un factor determinante en el proceso de investigación o de aprendizaje, alrededor de un 
término, "la administración”. Término que se refiere al manido esquema del planificar, hacer, verificar y actuar, pero que cae acertadamente en este punto. Las nuevas tecnologías rebasarán el término escueto del aprendiz y lo llevarán a ser un planificador de su aprendizaje o de su investigación, lo mismo que un hacedor o un actor, un verificador y un personaje práctico, con sus múltiples facetas derivadas de este marco administrativo.

Las nuevas tecnologías nos brindan la posibilidad de transformar la educación, la didáctica, la docencia, la pedagogía, la investigación. La llamada sociedad del conocimiento nos plantea nuevos retos, diversas formas de mirar el entorno, múltiples accesos a la información y a la comunicación, posibilidades y alcances para transformar los métodos, la manera de formar, de enseñar y aprender. La apertura de espacios brinda un campus y un aula virtual que eliminan barreras de tiempo y de lugar. Las nuevas generaciones, administradoras de las tecnologías, empujan de la misma manera a quienes los anteceden como a los que los preceden y nos hacen dar un viraje en nuestra forma de ver el mundo. El reto se encuentra ante nuestros ojos: prácticamente no existe otro camino: nos valemos de las nuevas tecnologías en nuestra docencia y en nuestra investigación o nos marginamos del proceso.

Parodiando el artículo que mencioné al principio ¿Y para qué leer?, me pregunto ahora, ¿̀ para qué me introduzco en el mundo de los computadores y de la informática? No para abandonar la lectura y no solamente para buscar nuevas didácticas, ni para visualizar otras formas de aprendizaje, formación e investigación, sino para encontrar, de alguna forma, lo mismo que en la lectura: la felicidad, que es el fin último del hombre, según nos lo enseña Santo Tomás de Aquino.

\section{Bibliografía}

ASIMOV, Isaac (1973). "Lo bien que se lo pasaban". En Nueva dimensión. Barcelona: Dronte.
BARRY J., Nalebuff y BRANDENBURGER, Adam M. (2005). Coo-petencia, Bogotá: Norma, pp. 316-317.

BORGES, Jorge Luis (1999). Atlas. Barcelona: Lumen.

BORGES, Jorge Luis (1980). Siete noches. México: Fondo de Cultura Económica, p. 18.

ALIGHIERI, Dante (1971). La divina comedia. Barcelona: Zeus.

LEER, Anne (2001). La visión de los líderes en la era digital. México: Pearson.

PARRA ROZO, Omar (1994). "¿Y para qué leer?". En Cuadernos de Filosofía Latinoamericana. Bogotá: USTA, pp. 45-48.

RUBIANO VARGAS, Roberto (1991). Alquimia de escritor. Bogotá: Intermedio Editores.

SAGAN, Carl (1985). La conexión cósmica. Barcelona: Orbis, p. 7.

STALLMAN, Richard M. (2006). "Conferencia sobre software libre". En Congreso mundial de educación superior a distancia. Bogotá: Universidad Abierta y a Distancia, UNAD.

www.asimovonline.com. Consultada: julio 30 de 2006.

http://www.colombialink.com/01_INDEX/ index_tecnologia/gurus/stallman.html Consultada: julio 22 de 2006.

www.educared.org.ar/guiadeletras/archivos/ asimov_isaac/index.htm. Consultada: julio 30 de 2006.

http://enciclopedia.us.es/index.php/Isaac_Asimov. Consultada: julio 30 de 2006.

http://enciclopedia.us.es/index.php/Richard_Stallman. Consultada: julio 22 de 2006. 


\section{(32) Universidad Santo Tomás}

http://funversion.universia.es/librospublicacion/reportaje/isaac_asimov.jsp. Consultada: julio 30 de 2006.

http://isaacasimov.garcia-cuervo.com/Biografia.htm. Consultada: julio 30 de 2006.

www.lachiva.com/2003/Mayo/29/caricatura.htm. Consultada: julio 28 de 2006.
http//fs-morente.filos.ucm.es/Publicaciones/ Iberpsicología/congreso/congreso.htm. Consultada: julio 24 de 2006.

www.stallman.org. Consultada: julio 22 de 2006.

unw.teacuerdas.com/nostalgia-series-mision.htm. Consultada: julio 25 de 2006. 